\title{
The transition home of extremely premature babies: An integrative review
}

\begin{abstract}
Taking a premature baby home after an often-protracted period on the neonatal unit can be stressful for parents and they are often confronted with an unexpected reality. The transition to motherhood and parenthood has occurred in the neonatal unit, under the watchful eye of neonatal nurses. When the baby goes home, parents are expected to take on the full-time caregiving role of a baby who may require around the clock care with medications, home oxygen, feeding issues and monitoring. The level of preparation for the transition home of the premature baby can impact on how the family survives and thrives. It is not surprising that parents may find this challenging because the growth and development trajectory of extremely premature babies can be markedly different from a term infant requiring tailored support to meet. This article is an integrative review of the literature focusing on parents' experience of transitioning home from a neonatal unit with a premature baby. Six themes were identified, and an analysis is presented: namely, transition, unique needs of premature babies, discharge preparation and readiness, discharge learning content, maternal mental health and the role of the neonatal nurse in transition.
\end{abstract}

\section{Key words}

Transition; Discharge home; Premature babies; Parents' experiences

\section{Introduction}

It is estimated that every year there are an estimated 1.5 million preterm babies delivered before the $37^{\text {th }}$ completed week of gestation (World Health Organization (WHO) 2017), equating to more than 1 in 10 babies born preterm worldwide (WHO, 2019). Most of these preterm births are in developing nations and the number worldwide is rising (WHO 2017). The Australian Institute of Health \& Welfare (AIHW, 2015) reported 8.7percent of births considered preterm and the UK currently reports (BLISS, 2020a). It is significant that prematurity is the leading cause of death in newborns under four weeks of age, and preterm birth complications are the leading cause of death among children under five years of age (Liu et al., 2016; UNICEF, 2019; WHO, 2019; BLISS, 2020b).

Premature birth is a significant life stressor for parents. Following the birth, the parents find themselves in an unfamiliar and technological environment which can be overwhelming, as 
they adjust to their new and early role as parents of an extremely premature baby (Fowler et al., 2019). Parents are grieving the loss of their expected pregnancy length, and the early arrival of a baby whose survival and immediate and long-term future outcome is uncertain (Aagaard et al., 2015). The baby's appearance can be a source of distress for the parents and could impact on their ability to bond with the baby (Green et al., 2015). Parental bonding is facilitated with behaviours such as a bedside vigil, touching, holding and interventions such as kangaroo care (Aydon et al., 2017). What makes this situation unique is the prolonged duration of the transition from hospital to home, with the hospitalization of a premature baby altering the process of transition to motherhood and parenthood (Hutchinson et al., 2012). Discharge of the baby marks two milestones; taking the infant home and becoming full-time parents (Raines, 2013). The discharge from the neonatal unit (NNU) can be both a joyous and stressful event as parents assume the fulltime caring role of their baby at home (BlakewellScahs \& Gennaro, 2004). Added to the complexity, many of these babies, particularly at the lower gestations, can acquire one or more significant disabilities necessitating the involvement of paediatric services (Boyle et al., 2011). These babies can also go home on medical devices and equipment such as oxygen therapy and parenteral nutrition.

This article provides an integrative review of the literature focusing on parents' experience of transitioning home from a neonatal intensive care unit with a premature infant. Six key themes were identified within the reviewed articles.

\section{Method}

An integrative review method was used for this literature review. Integrative reviews are used to introduce new or emerging topics to provide an initial conceptualisation of a topic (Torraco, 2005). This integrative review was guided by the work of Whittemore and Knafl (2005). It allows a diverse range of research to be incorporated into the review (Whittemore \& Knafl, 2005). The initial focus of this review was on extremely premature babies. However, after the first review process was concluded it was identified that there was insufficient literature focused on the extremely premature infant, so a second review question was identified that broadened the search to focus on premature infants who are 32-weeks and less. The final question identified for this review was: How do parents experience the transition home from a neonatal intensive care unit with an extremely premature infant (less than 32-weeks gestational age)? 


\section{Inclusion criteria}

The inclusion criteria required articles to report quantitative and qualitative studies and literature reviews published between 2010-to-2020. These articles needed to provide specific interventions to support the transition home from neonatal units of infants less than 32-weeks gestation. The articles must be full text and written in English.

\section{Search strategy}

The integrative review between 2010-and-2020 was facilitated through a search of the literature using multiple health-care related databases: CINAHL, Medline, PsychInfo, Embase, Maternity and Infant Care and Google Scholar. (see Table 1: literature search terms).

Table 1: Literature search terms

\begin{tabular}{|c|c|c|}
\hline A. Discharge Terms & $\begin{array}{l}\text { B. Prematurity } \\
\text { terms }\end{array}$ & C. Parent terms \\
\hline $\begin{array}{l}\text { (Neonatal OR Neonatal intensive } \\
\text { care OR Neonatal intensive care } \\
\text { unit OR Neonatal intensive care } \\
\text { nursing) AND (Discharge OR } \\
\text { Transfer OR Patient discharge } \\
\text { OR Discharge planning) }\end{array}$ & $\begin{array}{l}\text { Premature birth OR } \\
\text { Premature childbirth OR } \\
\text { Premature infant }\end{array}$ & $\begin{array}{l}\text { Parent OR } \\
\text { Parental attitudes OR } \\
\text { Parent-infant relations }\end{array}$ \\
\hline OR & OR & OR \\
\hline $\begin{array}{l}\text { (Readiness) AND (Discharge OR } \\
\text { Transfer OR Patient discharge } \\
\text { OR Discharge planning) }\end{array}$ & $\begin{array}{l}\text { Preterm birth OR } \\
\text { Preterm childbirth }\end{array}$ & $\begin{array}{l}\text { Mother OR } \\
\text { Mother-child relations OR } \\
\text { Maternal }\end{array}$ \\
\hline OR & OR & OR \\
\hline \multirow[t]{3}{*}{ After care } & Low birth weight infant & $\begin{array}{l}\text { Father OR } \\
\text { Father-infant relations OR } \\
\text { Paternal }\end{array}$ \\
\hline & OR & \\
\hline & Neonatal intensive care & \\
\hline
\end{tabular}


The results from the three searches (A, B and C) were combined with the term AND. The grey literature and reference lists of selected articles were reviewed for any missing articles. As the initial search for literature related to extremely preterm babies only resulted in three articles, an expanded search for research about babies 32-weeks and less was conducted. Once broadened the search resulted in an additional 40 articles. Each study was initially screened through the abstract and title for relevance with an in-depth read of the papers showed promise to meet the inclusion guidelines. There were thirty-two articles that met the review criteria.

\section{Data analysis}

A thematic analysis was conducted to identify the key themes within the included articles. A table of evidence was constructed by the first two authors to further guide the analysis. The other two authors verified the analysis and the inclusion of articles (see Appendix: evidence table).

\section{Results}

A total of thirty-two articles were identified and included in this review. Six themes were identified within the reviewed articles: transition; unique needs of premature babies; discharge preparation and readiness for discharge; necessary discharge learning content; maternal mental health; and role of neonatal nurses in transition.

\section{Study characteristics}

Research methods used within the included articles consisted of qualitative (twenty articles) and quantitative studies (two articles), mixed methods (six articles) and literature reviews (four articles). The twenty-eight research articles used for the review were from twelve countries (see Table 2: Research country of origin) along with a further four literature reviews (Adama et al., 2016; Lopez et al., 2012; Setaiwan et al, 2019; Smith et al., 2013). 
Table 2: Research country of origin

\begin{tabular}{|c|c|c|}
\hline Country & & \\
\hline Australia & $\begin{array}{l}\text { Adama et al (2016) } \\
\text { Aydon et al } 2017 \\
\text { Fowler et al. (2019) } \\
\text { Setaiwan et al (2019) }\end{array}$ & \\
\hline Brazil & deSouza et al (2010) & \\
\hline Canada & $\begin{array}{l}\text { Burnham et al (2013) } \\
\text { Murdoch \& Franck (2012) }\end{array}$ & \\
\hline Denmark & $\begin{array}{l}\text { Breivold et al (2019) } \\
\text { Koreska et al (2019) }\end{array}$ & \\
\hline China & Chen et al (2015) & \\
\hline Iran & Zamanzadeh et al (2013) & \\
\hline Italy & Spinelli et al (2015) & \\
\hline Norway & Voie et al (2018) & \\
\hline Sweden & Lundqvist et al (2019) & \\
\hline Switzerland & Rio et al (2020) & \\
\hline United Kingdom & $\begin{array}{l}\text { Fleming et al (2017) } \\
\text { Ingram et al (2017) } \\
\text { Petty et al (2018) }\end{array}$ & \\
\hline $\begin{array}{l}\text { United States of } \\
\text { America }\end{array}$ & $\begin{array}{l}\text { Berman et al (2019) } \\
\text { Enlow et al (2014) } \\
\text { Garfield, Lee \& Kim (2014) } \\
\text { Hutchinson et al (2012) } \\
\text { Lakshmanan, et al (2019) } \\
\text { Phillips-Pula et al (2013) } \\
\text { Smith, et al (2012, 2013) }\end{array}$ & $\begin{array}{l}\text { Boykova (2016) } \\
\text { Fratantoni et al (2016) } \\
\text { Griffin \& Pickler (2011) } \\
\text { Lakshmanan, et al (2017) } \\
\text { Lopez et al (2012) } \\
\text { Raines (2013) }\end{array}$ \\
\hline
\end{tabular}




\section{Transition}

The admission of a baby to the neonatal unit is a significant source of stress for parents and the transitioning home with a baby with complex medical needs can compound this stress for the parents (Garfield et al., 2014). Despite any preparation by staff, the research on transition home emphasises that parents often feel unprepared for discharge (Garfield et al., 2014). Transition has been described as a passage from one life span to another, encompassing process, timespan and perception. The transition process has an entry, passage, and an exit, and during the transition phase an individual must structure a new reality, and in the case of the parents transitioning home from the neonatal unit they go from "not being a parent" to "being a parent" (Hutchinson et al. 2012., p. 17).

Recently, Lakshmanan et al. 2019) highlighted the limited information on families' experiences during transition and after discharge from the neonatal unit. Their conceptual model described families' challenges and ideas to support transition; namely: comparison to normal babies, caregiver mental health and the need for information. Proposed ideas to support transition included provision of adequate support systems, interventions using mobile health technology, improved communication to the family and information regarding practical support at home. (Lundqvist et al (2019) supports these conclusions and proposed that the journey from birth to discharge from hospital affected what they called 'the parents' lifeworld"' (pg. 2966). Mothers experienced physiological reactions that triggered feelings of existential loneliness and guilt and difficulties in the role of mother. The fathers faced conflicts managing their partners' demands, family challenges including those from their employers, which negatively affected the transition into home life after the neonatal unit. An integrative thematic literature review by Setaiwan et al (2019) similarly revealed key themes relating to transition home: establishing parenting; bonding; psychological distress; and the need for information, resources and support, highlighting consistent parental concerns regarding discharge from the neonatal unit. Therefore, support from the healthcare team plays a crucial role during the experience.

A comprehensive and coordinated approach to transition is essential to help parents emerge from their neonatal experience with increased competence and confidence in infant caregiving (Jefferies, 2014). However, there is evidence that families do not always feel 
adequately prepared to take their baby home (Boykova, 2016; Petty et al, 2018). This will be further discussed later.

\section{Unique needs of premature babies}

Caring for a newborn at home is demanding and time-consuming. A neonatal unit graduate with ongoing and often complex medical needs related to their extreme prematurity intensifies those demands (Raines, 2013). The intensity of care needed by the growing premature baby and the high level of vigilance required can adversely affect the parents' and family's quality of life (Lakshmanan et al., 2017). When the baby transitions home, mothers recognised that their babies were identified as 'abnormal' or rather 'different' to expected norms; this was amplified as they were no longer compared to other premature babies (Murdoch \& Franck, 2012). After discharge, a constant emotion parents experienced was fear (Adama et al., 2016). In their literature review Adama et al. (2016) identified that this was related to the baby's fragile state and their associated health conditions along with the constant risk of deterioration. These concerns and fears were attributed to a lack of knowledge about caring for the specific needs of these vulnerable babies. Parents need anticipatory guidance to help them gain a realistic idea of what life will be like in the short and long term when taking their extremely premature infant home (Smith et al., 2013). Lundqvist et al's (2019) study concurs, emphasising how important it is for the nursing and healthcare team to help parents clarify their individual needs in caring for a preterm infant and to help them achieve optimum parental and family well-being.

Parents' concerns about ongoing health problems were reported to include oesophageal reflux and chronic lung disease (Petty et al., 2018). Re-hospitalisation was also a continuing issue for these parents, as stated previously. Typical infant behaviours expected in full term infants are not so typical in growing premature babies. Growing premature babies have a different "normal" trajectory and if parents do not know what to expect, then the behaviour of their baby may cause anxiety and fear in parents. Therefore, knowledge about the differing needs and behaviours of full term and premature babies, even correcting for age, would be helpful for parents (Smith et al., 2013). Differences in behaviour include preterm infants frequently not engaging socially in the same way as term infants. They are also often less active, alert and responsive and can be more irritable with greater levels of gaze aversion than term infants (Smith et al., 2013). 
More recently and serving as a clear summary of the above points, Berman et al (2019) found that parents who have experienced neonatal discharge have a spectrum of needs that evolve from the time the baby is in the neonatal unit, at the time of discharge, and then at home. These needs consistently related to five themes - communication, clarity in the parent role, emotional support, knowledge sources, and financial resources.

A study by Breivold et al (2019) adds further support to this. These authors found a main theme analysed from parents views that they named as 'Seeing the light at the end of the tunnel' with four categories relating to family needs; 'Finding a safe haven at home', 'Gaining support and learning to ensure optimal feeding', 'Seeing the child's possibilities' and 'Receiving professional attention and reassurance'. In particular, adequate breastfeeding guidance and help with practical tasks at home were emphasised as important for the mothers. Practical help and support by professional follow-up were important to assist mothers' ability to cope with the transition home, with a strong focus on breastfeeding guidance since many mothers experienced problems for significant time after discharge, often expressing they had missed out on breastfeeding guidance given to term babies.

\section{Discharge preparation and readiness}

Parents are often unprepared for discharge; for some, this was due to a lack of discharge notice (Hutchinson et al., 2012). The prospect of discharge provokes a range of uncertainties in parents that are often not addressed in the process leading up to the actual date to go home. Discharge preparation that includes development of parenting skills should begin shortly after admission and continue until the families are ready and prepared to take their babies home (Smith et al., 2013). Discharge education can improve parent readiness for their premature baby's discharge, and the quality of discharge teaching impacts on the parental readiness (Chen et al., 2016).

Discharge teaching needs to focus on the readiness to learn, learning needs and learning styles of the parents and not solely on the technologies and medical treatments needed by the infant (Raines, 2013). For mothers, in a study by Burnham et al. (2013), perceiving their baby ready for discharge was found to be a key factor in whether or not they saw themselves as ready. Parents took cues from their baby and often interpreted the staff's behaviours as indicative information that they were heading for discharge. Such indicators included the 
baby coming off monitoring devices because of a reduction in apnoea and bradycardia episodes associated with brain stem maturity, the baby approaching his/her estimated birth date with corresponding weight gain and growth, the infant feeding well at the bottle or the breast, and/or the mother being competent with naso-gastric feeds. The bed position could signal to the parents the progression towards discharge when the baby moves from the acute area to the step-down nursery (Burnham et al., 2013). When parents were informed about the routine tests prior to discharge such as hearing, this reinforced that discharge was becoming closer. It is important to remember that when a baby has monitoring devices attached, the family perceive the baby as being sick (Burnham et al., 2013), so it is important to ensure that monitoring is not removed on the day of discharge. In fact, Garfield et al. (2013) emphasise that the neonatal unit's reliance on electronic monitoring up until discharge makes parents understandably question their own abilities to monitor their baby once at home.

Face-to-face conversation with parents was a favoured method of receiving information in Burnham et al's (2013) study as they could ask questions and seek clarification. The informal conversations with neonatal nurses at the baby's bedside were considered a valuable way to receive information. It is difficult to know the best time to give parents information about discharge. Not surprisingly, some parents felt that preparation should begin on admission, while others considered a few days to a week prior to discharge would be adequate (Burnham et al., 2013). What could make the difference would be the level of involvement in caregiving activities of the parents for the duration of their baby's stay in the neonatal unit. When parents spent time with their baby in the neonatal unit, it allowed them to witness their baby's progression from admission to discharge, and all of the differences along the way. Smith et al. (2013) suggest the gradual introduction of information and skills early in the neonatal unit stay allows families the time to gain the necessary knowledge, skills and confidence about caring for their baby, therefore decreasing the feeling of being overwhelmed with teaching in the days just before discharge. Most parents in Burnham et al's. (2013) agreed that waiting until the day of discharge was too late to receive information. A structured program called Train-to-Home was successfully implemented to prepare parents for transition home. It assisted in increasing the communication between parents and staff providing booklets and other visual aids (Ingram et al., 2017).

Mothers in a study by Phillips-Pula et al. (2013) acknowledged that they needed to be told, retold, and told again how to do things for their infants. At times the mothers felt so stressed 
and were not able to grasp what was being told to them. It was not surprising that the mothers in Phillips-Pula et al's (2013) study wanted important information and instructions reinforced several times before discharge in order for them to have a complete understanding. It is not until parents assume full care of their baby's complex needs; do they truly get an understanding of how they will manage the baby. The ideal time for 'rooming-in' on the neonatal unit with their baby seems to be three to four days before discharge (Smith et al., 2013).

Discharge readiness is defined as the masterful attainment of technical skills and knowledge, emotional comfort and confidence with infant care by primary caregiver (Smith et al,.2013). Discharge readiness would be a combination of all the processes involved in the transition from the neonatal unit to home, with the family feeling confident to take the baby home and feeling competent to provide for the ongoing care of the baby. It is interesting that parents rated themselves as more prepared for the discharge than the nurses (Garfield et al., 2014). It is important to remember that re-admission to paediatric services within 30 days after discharge from hospital has been linked to not being ready for discharge (Smith et al., 2013).

The timing of a high-risk infant's discharge should be based on when the baby is able to coordinate breathing and oral feed, ingest adequate volumes for weight gain, maintain body temperature in an open environment and maintain stable cardio-respiratory function (Smith et al., 2013). However, it is important to remember that the baby could also be tube fed, have monitoring devices, oxygen therapy, tracheostomy and/or ventilation devices and even home parenteral nutrition.

In Berman et al's (2019) study, parents described ways in which the healthcare system could have facilitated readiness, helping them to be better prepared and more connected them with essential resources. The authors have compiled a useful series of practical recommendations based on the parent voice to use to assist parents to feel prepared and confident for the transition home from the neonatal unit. These include "dress rehearsals"' and increased participation and ownership of care by parents while on the neonatal unit. 


\section{Discharge learning content}

The information and learning needs of parents are far more complex than most parents experience due to the health needs of their baby. Individual learning styles need to be considered to enhance the intake of knowledge. Parents have identified that general categories that need to be covered are basic baby care; knowing when their baby is doing well; care for the baby at home; expectations for after discharge; things to observe for; and management of unexpected health issues specifically emergency concerns (Burnham et al., 2013). Discharge teaching should cover these specific needs of the extremely premature baby such as breastfeeding, formula milk and bottle preparation, feeding, feeding patterns and infant cues, normal bowel and bladder function. The specifics of feeding the growing extremely premature baby would have to be one of the most important skills that parents need to learn, because feeding and nutrition-related issues are the most common problems reported after discharge (Burnham et al. 2013; Smith et al. 2013). Parents in a study by Burnham et al (2013) believed that knowledge and skill in infant feeding were as important as weight gain and a major focus during hospitalisation. Preterm infants are more prone to feeding issues such as poor sucking, gastro-oesophageal reflux and difficulties co-ordinating breathing and swallowing. Parents need to be proficient in cardiopulmonary resuscitation skills and know how to manage an emergency. These skills are important because approximately 21 percent of babies born prematurely between twenty-four and thirty-six weeks gestation have at least one life-threatening event after neonatal unit discharge (Smith et al., 2013). Another example of specific content is provided by Fleming et al (2017) who document outcomes from the development of a simple chart for date of discharge from hospital. This allowed staff and parents to predict the likely discharge date, in turn then enabling better and more timely planning for discharge home. This is particularly important given the recent earlier discharges of preterm babies seen, whereby there is less time for parents to prepare and gain the necessary skills and understanding of vital care needs after discharge.

It has been suggested that standardised teaching material should be available to ensure consistency of teaching (Smith et al., 2013). Mothers in a study by Zamanzadeh et al. (2013) were concerned about the quality of discharge preparation because the nurses were very busy, and the nurse-to-patient ratio was inadequate. The rate of hospitalisation of premature babies discharged from the neonatal unit is up to $50 \%$ (Raines, 2013). Clearly, the finding that mothers are concerned that they will miss a change in their baby's condition is reasonable 
and means that discharge teaching needs to incorporate information to give the parents an understanding of what to look for, and how to tell if their baby is sick. Teaching for discharge preparation is clearly imperative. Most recently, a correlational study by Rio et al (2020) found the perceived quality of teaching positively predicted readiness for discharge. Mothers felt mostly ready and well prepared to go home if teaching was adequate although after discharge, a significant number had used health services in an unplanned manner. They recommend further exploration of reasons leading to this high rate of usage of post discharge healthcare.

\section{Maternal mental health}

Maternal mental health is a significant issue for mothers with preterm infants. When the baby is in the neonatal unit, mothers experience separation, emotional distress at the severity of the baby's illness. The stress associated with the fluctuations mirror the ups and downs of the baby's condition (Raines, 2013). Mothers are likely to feel that they have missed out on the normal expectations of motherhood as being joyful. This was replaced with feelings of not coping, guilt, failure and hypervigilance (Fowler et al., 2018; Petty et al., 2018).

Maternal mental health is a significant issue for mothers with preterm infants who have complex emotions including feeling fearful and insecure (deSouza et al., 2010; Fratantoni et al., 2016; Murdoch \& Franck 2012; Fowler et al., 2018). Mothers can be concerned about the relationship with their babies (Spinelli, 2015). It is well established that mothers with preterm infants who have been admitted to a neonatal unit experience psychological distress (Adama, 2016). Mothers identified that they felt under pressure and were constantly worried resulting in a continuing nightmare (Zamanzadeh et al., 2013). Maternal mental health problems such as depression and anxiety can result in poor bonding and attachment between mother and infant (Smith et al., 2013). Mothers and their partners need support to learn resilience strategies to manage their concerns (Garfield, 2014). These strategies include the provision of professional support to assist in decreasing stress and improving infant outcomes (Garfield, 2014). Social support is a crucial element that is strongly linked to improving the mental health of mothers (Lakshmanan et al., 2017; 2019). 


\section{Role of neonatal nurses in transition}

Neonatal nurses are fundamental in their role in helping families prepare for discharge (Burnham et al., 2013) as parents require enhanced professional support (Boykova, 2016). Nurse involvement is identified as a key element in all transitional programs (Lopez et al., 2012). Nurses are uniquely positioned to individualize interventions aimed at enhancing parents' readiness for discharge (Burnham et al., 2013). Parents in a study by Burnham et al. (2013) described how taking on their baby's care while still in the safe environment of the neonatal unit with neonatal nursing support was crucial for building confidence in their caregiving abilities and enhancing their readiness for discharge. Once in the community a knowledge deficit in community nurses and other health professions can cause the parents to lose confidence (Fowler et al., 2018; Petty et al., 2018). Of note, are the barriers to accessing service and information encounter after discharge including scheduling appointments, filling prescriptions, knowing who to call when baby unwell, and finding transportation (Enlow et al. 2014) and communicating with health professionals (Aydon et al., 2017; Griffin \& Pickler, 2011).

Understandably, parents are anxious about their ability to care for their baby when they are discharged home, without the help of neonatal unit nurses (Raines, 2017). Neonatal nurses are in the perfect position by virtue of the amount of time that they spend with parents in the neonatal unit, to help uncover and address the parent's concerns about discharge and provide the relevant information (Raines, 2013). Raines (2013) emphasises that mothers often do not disclose their concerns due to fear of failure, guilt, disappointment, loss of self-esteem and even a fear of delaying their baby's discharge.

This can be a barrier to the role of nurses and health professionals in the community being able to provide the tailored support needed. Another barrier may be lack of collaboration between neonatal staff and community-based health professionals. Voie et al (2018) explored the collaboration challenges faced by these two professional groups when preparing premature infants for transition home and the culture of cooperation. Different expectations and lack of communication between them were highlighted and responsibilities and interactions between roles were not clearly defined. This study concluded that there is a vital need for clear guidelines about the neonatal discharge process and the specific needs of parents, a conclusion corroborated in a later study by Petty et al (2019). 
Most recently, a study by Koreska et al (2020) illustrated how discharge nurses on the neonatal unit can facilitate a partnership with families enrolled using a range of strategies to adjust their care to the family's needs. Discharge nurses should have a clear understanding of family needs and play a unique role by facilitating a partnership that supports the family on the journey towards a normal everyday life.

\section{Discussion}

Caring for a newborn at home is demanding and time-consuming. A neonatal unit graduate with ongoing and often complex medical needs related to their extreme prematurity intensifies those demands (Berman et al., 2019; Breivold et al., 2019; Rio et al., 2020; Setiawan, 2020). Parents and their premature infants require significant support to make the transition from neonatal unit to home.

The preparation for discharge needs to commence as soon as possible after the birth of the baby to enable parents to learn the necessary knowledge and skills to confidently care for their baby at home (Burnham et al., 2013). Parents require anticipatory guidance, so they are prepared for potential problems or unexpected behaviours and to develop realistic expectation of their baby and their parenting abilities (Smith et al., 2013). Preparation requires the parent to be emotionally stabilise and manage the trauma of having a premature baby, the experience of being in a neonatal unit and seeing their baby and other babies die or have invasive treatments (Fowler et al., 2018). Stress prior to learning is known to reduce memory (Schwabe \& Wolf 2010) this will require the transfer of information and skill to be carefully planned and often repeated several times. In research involving adults it was found that the quality of discharge teaching was the strongest predictor of discharge readiness (Weiss et al., 2007).

Maternal mental health is fundamental to the well-being and development of the premature baby, both in the neonatal unit and at home, however mothers of premature babies have been found to have higher rates of depression, anxiety, acute and post-traumatic stress reactions (Baum et al., 2012). Mothers have described the time following neonatal unit discharge as being the most difficult of their lives, with anxiety lasting for up to two years (Griffin \& Abraham, 2006). Clearly, this can impact on the outcome of the growing premature baby and can even impact the future mental health of the baby. Evidence is mounting that babies less than 1000 grams are at an increased risk of mental health problems into childhood, 
adolescence and now adulthood (Johnson \& Marlow, 2014). Discharge planning begins at the bedside after admission to the neonatal unit (Aydon et al., 2017); However, the best way to operationalise discharge planning and transition to discharge has not been established.

There are numerous implications for practices (see Table 3: recommendations for practice).

Table 3: Recommendations for practice

1. Commence discharge education as soon as possible after admission neonatal unit

2. Align the teaching provided to the individual learning style of the parent

3. Provide hard or digital copies of critical information

4. Be prepared to repeat information and make opportunities for parents to practice new skills

5. Encourage parents to be increasingly more involved with their infant's care

6. Assist the mother develop a support network. In the digital age this would include online support groups.

7. Maternal mental health needs to be regularly assessed during the neonatal unit admission and after discharge home

8. Provide education for community health professionals to help them understand the unique needs of growing premature babies

A missing research focus is investigating the knowledge and skill base for community health professionals. When the baby and family leave the neonatal unit, community health professionals are required to provide a significant ongoing care and support role for the baby and family. This is well documented in the literature, however there is no evidence that these health professionals know about the unique needs of the growing premature baby and his/her different developmental trajectory. Perhaps this is one reason why there is an increased rate of re-hospitalisation in these babies. When the baby is taken to a health care provider who does not know whether a behaviour or issue is normal or abnormal for a growing premature baby, the baby and family are often escalated into paediatric hospital services. Yet, there does seem to be some evidence that health providers in acute paediatric or community services may not understand the nuanced and ongoing needs of these growing premature babies (Petty et al., 2019; Rio et al., 2020). With an increase in the number of premature babies surviving at lower gestations, this education would seem to be an imperative. 


\section{Conclusion}

The experience of having an extremely premature baby is recognised as potentially having a long-term profound effect on parents. Quality parenting is essential for the best developmental outcome of the baby, but this will also impact on the outcome of family wellbeing. A review of the literature on the transition home of extremely premature babies supports the idea that families are often not adequately prepared for the hospital discharge of their babies. The lack of preparation contributes to heightened maternal anxiety, poorer infant outcomes and a higher than expected utilisation of health-care resources and re-admission to hospital. Parental involvement in caregiving is essential to help parents emerge from the neonatal unit, feeling confident and competent to care for their baby. The quality of discharge teaching is a strong predictor of discharge readiness; therefore, a systemic and individualised approach will help families, yet what is needed is education for the health professionals who will take over the ongoing and often long-term care of the baby and family. 


\section{References}

Aagaard, H., Uhrenfeldt, L., Spliid, M., Fegran, L., 2015. Parents' experiences of transition when their infants are discharged from the Neonatal Intensive Care Unit: A systematic review protocol. JBI database of Systematic Reviews and Implementation Reports. 13(10), 123-132.

Adama, E. A., Bayes, S., Sundin, D., 2016. Parents' experiences of caring for preterm infants after discharge from neonatal intensive care unit: a meta-synthesis of the literature. Journal of Neonatal Nursing, 22(1), 27-51.

Australian Institute of Health and Welfare. 2017. Australia's mothers and babies. 2015 in brief. Accessed 12/09/2020.

https://www.aihw.gov.au/reports/mothers-babies/australias-mothers-babies-2015-inbrief/contents/table-of-contents

Aydon, L., Hauck, Y., Murdoch, J., Siu, D., Sharp, M., 2017. Transition from hospital to home: Parents perception of their preparation and readiness for discharge with their preterm infant. Journal of Clinical Nursing. 27(1-2), 269-277

Bakewell-Sachs, S., Gennaro, S., 2004. Parenting the post-neonatal unit premature infant. MCN: The American Journal of Maternal/Child Nursing. 29(6), 398-403.

Baum, N., Weidberg, Z., Osher, Y., Kohelet, D., 2012. No longer pregnant, not yet a mother: Giving birth prematurely to a very-low-birth-weight baby. Qualitative Health Research. 22(5), 595-606.

Berman, L., Raval, M. V., Ottosen, M., Mackow, A. K., Cho, M., \& Goldin, A. B., 2019. Parent perspectives on readiness for discharge home after neonatal intensive care unit admission. The Journal of Pediatrics. 205, 98-104.

BLISS 2020a. Prematurity Statistics in the UK. Accessed 12/09/20. https://www.bliss.org.uk/research-campaigns/neonatal-care-statistics/prematurity-statisticsin-the-uk

BLISS 2020b. The Global Picture. Accessed 12/09/20. https://www.bliss.org.uk/researchcampaigns/neonatal-care-statistics/the-global-picture

Boykova, M., 2016. Life After Discharge: What Parents of Preterm Infants Say About Their Transition to Home. Newborn and Infant Nursing Reviews. 16(2), 58-65.

Boyle C.A, Boulet S, Schieve L.A, Cohen R.A, Blumberg S.J, Yeargin-Allsopp M, Visser S, Kogan M.D., 2011. Trends in the prevalence of developmental disabilities in US children, 1997-2008. Pediatrics, 127(6), 1034-1042.

Breivold, K., Hjaelmhult, E., Sjöström-Strand, A., \& Hallström, I. K., 2019. Mothers' experiences after coming home from the hospital with a moderately to late preterm infant-a qualitative study. Scandinavian Journal of Caring Sciences, 33(3), 632-640.

Burnham, N., Feeley, N., Sherrard, K., 2013. Parents' perceptions regarding readiness for their infant's discharge from the neonatal unit. Neonatal Network: The Journal of Neonatal Nursing. 32(5), 324-334. 
Chen, Y., Zhang, J., Bai, J., 2016. Effect of an educational intervention on parental readiness for premature infant discharge from the neonatal intensive care units. Journal of Advanced Nursing. 72(1), 135-146.

de Souza N, Pinheiro-Fernandes A, Clara-Costa I, Cruz-Enders B, de Carvalho, J., de Silva M., 2010. Domestic maternal experience with preterm newborn children, Revista de Salud Pública. 12(3), 356-367.

Enlow, E., Herbert, S., Jovel, I., Lorch, S., Anderson, C., Chamberlain, L., 2014. Neonatal intensive care unit to home: the transition from parent and pediatrician perspectives: A prospective cohort study. Journal of Perinatology. 34(10), 761-766.

European Foundation for the Care of the Newborn Infant (EFCNI), Damhuis G, König K et al., 2018. European Standards of Care for Newborn Health: Case management and transition to home. https://newborn-health-standards.org/case-management-transition-home/

Fleming PJ, Ingram J, Johnson D, et al., 2017. Estimating discharge dates using routinely collected data: improving the preparedness of parents of preterm infants for discharge home. Archives of Disease in Childhood - Fetal and Neonatal Edition. 102: F170-F172.

Fowler, C., Green, J., Elliott, D., Petty, J., Whiting, L., 2019. The forgotten mothers of extremely preterm babies: A qualitative study. Journal of Clinical Nursing. 28(11-12), 21242134.

Fratantoni, K., Waters, D., Tuchman, L., Jiggetts, M., Soghier, L., 2016. Understanding the needs of families after neonatal unit discharge to inform a peer support program.

Developmental Medicine and Child Neurology. 58(S5), 89-90.

Garfield, C., Lee, Y., Kim, H., 2014. Paternal and maternal concerns for their very low-birthweight infants transitioning from the neonatal unit to home. The Journal of Perinatal \& Neonatal Nursing. 28(4), 305-312.

Green, J., Darbyshire, P., Adams, A., Jackson, D., 2015. Looking like a proper baby: Nurses' experiences of caring for extremely premature infants. Journal of Clinical Nursing. 24(1-2), 81-89.

Griffin, J., Pickler, R., 2011. Hospital-to-home transition of mothers of preterm infants. MCN, The American Journal of Maternal/Child Nursing. 36(4), 252-257.

Griffin, T., Abraham, M., 2006. Transition to home from the newborn intensive care unit: Applying the principles of family-centered care to the discharge process. The Journal of Perinatal \& Neonatal Nursing. 20(3), 243-249.

Hutchinson, S., Spillett, M., Cronin, M., 2012. Parents' Experiences during their Infant's Transition from Neonatal Intensive Care Unit to Home: A Qualitative Study. The Qualitative Report. 17(12), 1-20.

Ingram, J., Redshaw, M., Manns, S., Beasant, L., Johnson, D., Fleming, P., Pontin, D., 2017. "Giving us hope": Parent and neonatal staff views and expectations of a planned familycentred discharge process (Train-to-Home). Health Expectations. 20(4), 751-759. 
Koreska, M., Petersen, M., Andersen, B. L., \& Brødsgaard, A., 2020. Supporting families on their journey towards a normal everyday life - facilitating partnership in an early discharge program for families with premature infants. Journal for Specialists in Pediatric Nursing, 25(1), e12274-n/a. doi:10.1111/jspn.12274

Johnson, S., Marlow, N., 2014. Growing up after extremely preterm birth: lifespan mental health outcomes. Seminars in Fetal and Neonatal Medicine 19(2), 97-104.

Lakshmanan, A., Agni, M., Lieu, T., Fleegler, E., Kipke, M., Friedlich, P.S., McCormick, M.C., Belfort, M.B., 2017. The impact of preterm birth $<37$ weeks on parents and families: a cross-sectional study in the 2 years after discharge from the neonatal intensive care unit. Health and Quality of Life Outcomes. 15(1), 38.

Lakshmanan, A., Kubicek, K., Williams, R. et al. (2019). Viewpoints from families for improving transition from NICU-to-home for infants with medical complexity at a safety net hospital: a qualitative study. BMC Pediatr 19, 223. https://doi.org/10.1186/s12887-019-16046

Lopez, G.L., Anderson, K.H., Feutchinger, J., 2012. Transition of premature infants from hospital to home life. Neonatal Network. 31(4), 207.

Liu, L., Oza, S., Hogan, D., Chu, Y., Perin, J., Zhu, J., ... \& Black, R. E., 2016. Global, regional, and national causes of under-5 mortality in 2000-15: an updated systematic analysis with implications for the Sustainable Development Goals. The Lancet, 388, 10063, 30273035 .

Lundqvist, P., Weis, J., \& Sivberg, B., 2019. Parents' journey caring for a preterm infant until discharge from hospital-based neonatal home care-A challenging process to cope with. Journal of Clinical Nursing, 28(15-16), 2966-2978. doi:10.1111/jocn.14891

Murdoch, M., Franck, L., 2012. Gaining confidence and perspective: a phenomenological study of mothers' lived experiences caring for infants at home after neonatal unit discharge Journal of Advanced Nursing 68(9), 2008-2020.

Petty, J, Whiting, L., Green, J., Fowler, C., Elliott, D., 2018. Parents' views on preparation to care for extremely premature infants at home, Nursing Children and Young People. 39(4), 22-27.

Petty, J., Whiting, L., Mosenthal, A., Fowler, C., Elliott, D., \& Green, J., 2019. The knowledge and learning needs of health professionals in providing support for parents of premature babies at home: A mixed-methods study. Journal of Neonatal Nursing, 25(6), $277-$ 284.

Phillips-Pula, L., Pickler, R., McGrath, J., Brown, L., Dusing, S., 2013. Caring for a Preterm Infant at Home: A Mother's Perspective. The Journal of Perinatal \& Neonatal Nursing, 27(4), 335-344.

Raines, D., 2013. Preparing for neonatal unit Discharge: Mothers' Concerns. Neonatal Network. 32(6), 399-403 
Raines, D.A., 2017. Simulation as Part of Discharge Teaching for Parents of Infants in the Neonatal Intensive Care Unit. MCN: The American Journal of Maternal/Child Nursing. 42(2), 95-100.

Rio, L., Tenthorey, C., \& Ramelet, A. S., 2020. Unplanned post discharge healthcare utilisation, discharge readiness, and perceived quality of teaching in mothers of neonates hospitalized in a neonatal intensive care unit: A descriptive and correlational study. Australian Critical Care. https://doi.org/10.1016/j.aucc.2020.07.001

Schwabe, L., Wolf, O.T., 2010. Learning under stress impairs memory formation. Neurobiology of Learning and Memory. 93(2), 183-188.

Setiawan, J., Mannix, T., \& Sweet, L., 2019. Understanding the Effects of Neonatal Early Discharge on Parents: A Literature Review. The Journal of Perinatal \& Neonatal Nursing, 33(2), 170-188.

Smith, V.C., Dukhovny, D., Zupancic, J. A., Gates, H.B., Pursley, D.M., 2012. Neonatal intensive care unit discharge preparedness: Primary care implications. Clinical Pediatrics. 51(5), 454-461.

Smith, V.C., Hwang, S.S., Dukhovny, D., Young, S., Pursley, D.M., 2013. Neonatal intensive care unit discharge preparation, family readiness and infant outcomes: Connecting the dots. Journal of Perinatology. 33(6), 415-421.

Spinelli M, Frigerio A, Montalli L, Fasolo M, Spada, S., Mangili, G., 2016. 'I still have difficulties feeling like a mother': The transition to motherhood of preterm infant's mothers, Psychology \& Health, 184-204. DOI: 10.1080/08870446.2015.1088015

Torraco, R., 2005 Writing integrative literature reviews: Guidelines and examples. Human Resource Development Review. 4, 356-367. DOI: 10.1177/1534484305278283

UNICEF. 2019. Levels and Trends in Child Mortality. United Nations Inter-Agency Group for Child Mortality Estimation. Report (2019). Retrieved from:

https://data.unicef.org/resources/levels-and-trends-in-child-mortality/

Voie, M., Tunby, J., \& Strømsvik, N., 2018.Collaboration challenges faced by nurses when premature infants are discharged. Nursing Children and Young People, 30(2), 3338.doi:10.7748/ncyp. 2018.e960.

Weiss, M.E., Piacentine, L.B., Lokken, L., Ancona, J., Archer, J., Gresser, S., Holmes, S.B., Toman, S., Toy, A. and Vega-Stromberg, T., 2007. Perceived readiness for hospital discharge in adult medical-surgical patients. Clin Nurse Spec. 21, 31-42.

Whittemore, R., Knafl, K., 2005. The integrative review: updated methodology. Journal of Advanced Nursing 52(5), 546-553

World Health Organisation (WHO). 2017. Preterm Birth. Accessed 2/12/2019. http://www.who.int/mediacentre/factsheets/fs363/en/

World Health Organisation (WHO). 2019. Newborn: Reducing Mortality. Accessed 14/07/20 https://www.who.int/news-room/fact-sheets/detail/newborns-reducing-mortality 
Zamanzadeh, V., Namnabati, M., Valizadeh, L., Badiee, Z., 2013. Mothers' experiences of infants' discharge in Iranian neonatal unit culture. Advances in Neonatal Care. 13(4), E1-E7. 